qualification of ACP facilitators and family physicians, education of all regional health care actors relevant for the care of $\mathrm{n} / \mathrm{h}$ residents, and coordination within and between participating institutions.

Primary hypothesis is a reduced rate of unwanted hospital admissions. Secondary hypotheses include increased rates of residents whose preferences are known and followed in predefined critical treatment decisions, residents dying in the $\mathrm{n} / \mathrm{h}$ (versus in hospital) according to their preference, and residents, their families, and their caregivers who appreciate congruence between treatment wanted and delivered. Additionally, we plan a comprehensive process evaluation and a health economic analysis.

Conclusion While ACP has been repeatedly shown to be clinically effective in $\mathrm{n} / \mathrm{h}$, recent data from the Netherlands indicate it may not. Our trial, funded by the Innovation Fund of the Federal Joint Commission, will provide elaborate, 8 days facilitator qualification involving 24 hours of role plays with simulated patients, and it will be the first to study hospitalisation rate in all residents of participating $\mathrm{n} / \mathrm{h}$.

\section{P42 ACP IMPLEMENTATION IN GERMANY: A PROGRESS REPORT OF THE POLITICAL FRAMEWORK AND ITS TRANSLATION INTO PRACTICE}

G Marckmann*, S Petri, J In der Schmitten. Ludwig-Maximilians-University Munich, Munich, Germany

\subsection{6/spcare-2019-ACPICONGRESSABS.125}

Background In December 2015，\$132g was introduced into Social Code Book V. It provides financial coverage of advance care planning (ACP) for residents in long-term care institutions and institutions for persons with disabilities. At the end of 2017, the sickness funds and care home providers defined the details of the implementation in a mutual agreement.

Methods Policy analysis with description and critical reflection of the relevant regulations and the current status of ACP implementation in Germany.

Results Since early 2018, German care homes can get reimbursement for ACP-facilitators (1/4 full time equivalent for 100 residents), who can be either employed by the care home, by its carrier or by a regional cooperating partner. The mutual agreement specifies the structure and content of the planning process and defines the qualification requirements for ACP-facilitators, but not for facilitator trainers. Furthermore, the agreement calls for intra- and inter-institutional coordination, but does not provide for adequate workforce. Since 2016, there have been courses qualifying some 270 ACP-facilitators and 35 trainers, and several institutional ACP implementations. To promote the quality of the ACPimplementations, a German ACP-association (the DiV-BVP e.V.) was founded in 2017 to further develop facilitator and trainer curricula using simulated patient supported role plays, the contents of ACP-conversations, and of their adequate documentation.

Conclusions While $\$ 132 \mathrm{~g}$ Social Code Book V provides a historic opportunity to implement ACP in German care homes, there are still major challenges to overcome, especially regarding facilitator qualification and institutional and regional implementation of the ACP system.

\section{P43 PUTTING PIECES TOGETHER - A MULTIDISCIPLINARY TEAM IMPLEMENTING RESPECTING CHOICES IN A QUATERNARY HEALTH SYSTEM DEMONSTRATING REAL CHANGE AND SUSTAINABILITY}

I Boettcher*. Spectrum Health, Grand Rapids, USA

\subsection{6/spcare-2019-ACPICONGRESSABS. 126}

The zenith of implementing the Respecting Choices systems approach to person centered and family oriented care is to provide person-centered decision making for each individual that honors current and future healthcare preferences. It is essential to understand that challenges exist for a quaternary health system to honor each individual's preferences. Challenges include but are not limited to; (1) assuring conversations are initiated and completed (2) broken or insufficient communication regarding healthcare preferences as result of conversations, and (3) difficulty in healthcare providers accessing information on preferences in real-time. This presentation will describe how a multidisciplinary ambulatory care team implemented this person centered decision making as foundational to achieving the quadruple aim. Outcomes include: For calendar year 2017: 334 enrolled. After enrollment: 90\% had a person centered decision making conversation started, 80\% had an Advance Directive uploaded into the EHR and 97\% had a documented code status. Median survival after enrollment is 36 months with a overall cost of care reduction of $\$ 455$ per member per month during the time enrolled in the program. Further, 70 (43\%) transferred to hospice with an average LOS in hospice of 50 days, and a median LOS in hospice of 29 days. This is compared to an overall hospice average LOS: 61.6 days and median LOS of 16 days. Likelihood to refer this program to others is $95 \%$. Provider satisfaction is one of the highest of the 3600 providers in the delivery system.

\section{P44 IMPROVING ADVANCE CARE PLANNING (ACP) DOCUMENTATION IN FREQUENT DEPARTMENT OF GERIATRIC MEDICINE (GRM) ADMITTERS WITH DEMENTIA IN AN ASIAN HOSPITAL}

N Ali*, M Piodena-Aportadera, R Chong, N Roslan, E Fan, E Ho. Tan Tock Seng Hospital, Singapore, Singapore

\subsection{6/spcare-2019-ACPICONGRESSABS.127}

Aim To improve the percentage of completed ACP documentation of eligible recurrent admitters (3 or more admissions within the last 1 year with no prior ACP documentation on admission) with background dementia to ward 7D under department of GRM from $7 \%$ to $60 \%$ within 6 months Implementation Micro and macro flow charts were created to evaluate the processes in conduct of ACP. Root causes for reduced ACP documentation were identified via Ishikawa diagram and Pareto Chart. Through multiple PDSA (Plan, Design, Study, Act) cycles, the following interventions were conducted: creation of mandated workflow for ACP, reminders to offer ACP and incorporation of ACP in clinical delivery through documentation of ACP status in interim discharge summary and daily clinical problem list.

Results Root causes for low ACP documentation were ACP was not mandatory as part of clinical service delivery, lack of 